\title{
Every step matters
}

Acute type A (I) aortic dissection remains a devastating disease associated with significant morbidity and mortality. Encouraging, however, was the recent update from the International Registry of Acute Dissection that reported significant improvements in outcomes during the past 2 decades. ${ }^{1}$ Even with an increased rate of surgical treatment (from $78 \%$ to $90 \%$ ), the operative mortality decreased from $25 \%$ to $18 \%(P=.003)$. This translates into a $28 \%$ decrease in the surgical mortality through the course of the study. This improvement is multifactorial and attributable to areas of improvement in all phases of care for the patient. Despite the progress, however, opportunity for improvement remains.

Mortality in acute type A (I) dissection results from either rupture or malperfusion, and it remains a continuing goal to address both of these issues throughout the patient's hospital course. Relevant to the surgeon are the steps required during the course of the operation. Operative mortality is dependent on many variables, which include cardiopulmonary bypass and temperature management, cannulation strategy, malperfusion mitigation, myocardial protection, resection of the tear, and the approach to the transverse arch, the aortic root, and the aortic valve. In dealing with acute type A (I) aortic dissection, many will focus on such issues as whether to replace the transverse arch to perform a valve-sparing aortic root procedure or to use moderate hypothermia with antegrade cerebral perfusion. $^{2-4}$ I would not suggest that these are unimportant - these are very important issues-however, we should consider all operative steps equally important.

The brief communication in this issue of the Journal by Hussain and colleagues ${ }^{5}$ provides a simple technique in which the cannulation strategy was modified to address the lower extremity malperfusion at the initiation of the procedure. The technique is relatively simple, as Hussain and colleagues ${ }^{5}$ modified the arterial circuit to address the malperfused left lower extremity while providing central arterial perfusion through the right axillary artery. By

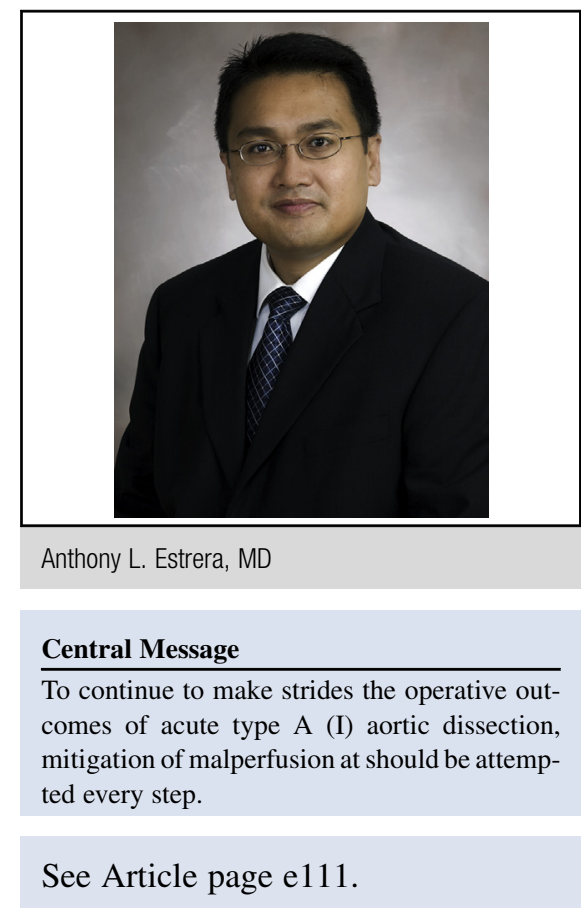

addressing this malperfusion at the initiation of the surgical procedure, as opposed to at the end, they potentially reduced the untoward effects of the persistent peripheral malperfusion.

My group recently reported our series of peripheral malperfusion after acute type A (I) aortic dissection and noted that $80 \%$ of peripheral malperfusion will be corrected by central repair alone. ${ }^{6}$ The $20 \%$ of patients who did not have improvement with central repair and required a peripheral intervention, whether open bypass or endovascular intervention, however, did have worse outcome with higher mortality. Although the higher mortality was attributable to involvement of other malperfused vascular beds, such as visceral and spinal, the persistent peripheral ischemia may have played a role. At any rate, what to address first and how should always be left to the operating surgeon.

In the end, improvement in the operative outcomes of acute type A (I) aortic dissection has occurred. We appreciate the detrimental effects of ischemia to all organ systems-related malperfusion. To continue to make strides, however, mitigating malperfusion at every step should be attempted. Thus, every step matters.

\section{References}

1. Pape LA, Awais M, Woznicki EM, Suzuki T, Trimarchi S, Evangelista A, et al. Presentation, diagnosis, and outcomes of acute aortic dissection: 17-year trends 
from the International Registry of Acute Aortic Dissection. J Am Coll Cardiol. 2015;66:350-8.

2. Halkos ME, Kerendi F, Myung R, Kilgo P, Puskas JD, Chen EP. Selective antegrade cerebral perfusion via right axillary artery cannulation reduces morbidity and mortality after proximal aortic surgery. J Thorac Cardiovasc Surg. 2009;138:1081-9.

3. Rice RD, Sandhu HK, Leake SS, Afifi RO, Azizzadeh A, CharltonOuw KM, et al. Is total arch replacement associated with worse outcomes during repair of acute type A aortic dissection? Ann Thorac Surg. 2015; 100:2159-66.
4. Rylski B, Beyersdorf F, Blanke P, Boos A, Hoffmann I, Dashkevich A, et al. Supracoronary ascending aortic replacement in patients with acute aortic dissection type A: what happens to the aortic root in the long run? J Thorac Cardiovasc Surg. 2013;146:285-90.

5. Hussain ST, Srivastava S, Johnston DR. Temporary axillofemoral bypass for reperfusion of an ischemic limb complicating type A dissection. J Thorac Cardiovasc Surg. 2016;151:e111-3.

6. Charlton-Ouw KM, Sritharan K, Leake SS, Sandhu HK, Miller CC III, Azizzadeh A, et al. Management of limb ischemia in acute proximal aortic dissection. J Vasc Surg. 2013;57:1023-9. 